\title{
Occupational Well-Being: A Structural Equation Model of Finnish and Estonian School
}

\author{
Sari Laine ${ }^{1}$, Kerttu Tossavainen ${ }^{1}$, Tiia Pertel ${ }^{2}$, Kädi Lepp $^{3}$, Hannu Isoaho ${ }^{4} \&$ Terhi Saaranen ${ }^{1}$ \\ ${ }^{1}$ Department of Nursing Science, University of Eastern Finland, Kuopio, Finland \\ ${ }^{2}$ National Institute for Health Development, Tallinn, Estonia \\ ${ }^{3}$ Tallinn University Haapsalu College/Foundation for School Health Care in Tallinn Development, Tallinn, \\ Estonia \\ ${ }^{4}$ Statcon Ltd, Salo, Finland \\ Correspondence: Sari Laine, Department of Nursing Science, University of Eastern Finland, P.O.BOX 1627, \\ Kuopio, Finland. Tel: 358-400-419698. E-mail: sari.laine@uef.fi
}

Received: June 5, 2018 Accepted: June 26, 2018 Online Published: July 11, 2018

doi:10.5539/gjhs.v10n8p79

URL: https://doi.org/10.5539/gjhs.v10n8p79

\begin{abstract}
This study aimed to test the original Occupational Well-being of School Staff Model (OWSS Model) from 2005. This model was tested using data collected in two stages (in 2010 and in 2013) from school staff in Finnish and Estonian public primary and secondary schools. In 2010, there were 486 Finnish respondents (Finnish study 1), and in 2013, there were 545 Finnish respondents (Finnish study 2). Correspondingly, there were 1330 Estonian respondents in 2010 (Estonian study 1), and 974 Estonian respondents in 2013 (Estonian study 2). Based on structural equation modelling, Finnish data from 2010 and 2013 suited the OWSS Model well. Based on Estonian data from 2010 and 2013, the model was slightly improved, but its main structures remained largely unchanged. On the whole, the results support the previous notion that the occupational well-being of school staff should be examined with reference to a broad spectrum of four viewpoints covering working conditions, worker and work, the working community and professional competence. General occupational well-being of the working community and subjective occupational well-being were best explained by working atmosphere and appreciation of others' work, especially in Finland. In Estonia, occupational well-being was best explained by working atmosphere and appreciation of others' work and working space, postures and equipment. Long-term testing with data from two countries and from two different testing periods confirmed that the model may continue to be applied in school contexts for planning, implementation and evaluation of occupational well-being, as well as for promoting public health.
\end{abstract}

Keywords: health promotion, occupational health, school, structural equation model, well-being, work

\section{Introduction}

There is no uniform definition of occupational well-being, although it plays a significant role from a public health point of view. It may be defined as a summative concept describing the quality of an individual's working life (occupational health and safety considerations included) (Schulte \& Vainio, 2010). It is perceived as a subjective (Juniper, 2011) and multidimensional phenomenon (Horn, Taris, Schaufeli, \& Schreurs, 2004; Juniper, 2011). The multidimensional structure consists, among other things, of emotional-related cognitive, occupational, social and psychosocial issues and dimensions, and it may be best described as a multidimensional model (Horn et al., 2004). Models developed for health promotion are useful tools for theoretical thinking and for the development of new strategies and new ways of working (Naidoo \& Wills, 2016).

The Job Demand-Control Model, also known as the Job Strain Model, may be perceived as the traditional model for addressing the origin of work-related stress (Karasek, 1979). Other traditional methods of addressing occupational well-being are the model of affective well-being (Warr, 1987; Warr, 1990) and the Effort-Reward Imbalance Model at Work, which is based on the relationship between work efforts and rewards (Siegrist, 1996). The Job Demands-Resources Model (Demerouti, Bakker, Nachreiner, \& Schaufeli, 2001) has been frequently used in studies on occupational well-being, as well as in school contexts (Hakanen, Bakker, \& Schaufeli, 2006; Vera, Salanova, \& Lorente, 2012; Salmela-Aro \& Upadyaya, 2014). In this model, occupational well-being is examined 
from the viewpoint of job demands (arising from physical, social and organizational factors, such as time pressure and workload) and resources (factors that help in achieving goals, coping and developing work skills, e.g., feedback, participation in decision-making and support from supervisors) (Demerouti et al., 2001).

Models describing occupational well-being have also been developed from the perspective of the school community. The Structural Equations Model of Demands, Personal Resources and Job Resources in Teacher Well-being, for example, is a model that describes teachers' well-being from the viewpoint of burnout and commitment, which not only reflect work demands and occupational resources (autonomy, social support from colleagues and supervisors, varying work tasks and feedback) but also subjective resources (self-efficacy and cognitive and behaviouristic resources for coping) (Bermejo-Toro, Prieto-Ursúa, \& Hernández, 2016). Occupational well-being in schools is also well described in the Occupational Well-being of School Staff Model (OWSS Model), in which occupational well-being comprises four aspects: working conditions, worker and work, working community and professional competence. In the OWSS Model, subjective well-being and the working community's well-being are explained from the perspective of all four aspects and the following factors: working spaces, postures and equipment (working conditions); workload (worker and work); working atmosphere and appreciation of others' work (working community) and substantive competence and interaction (professional competence) (Saaranen, Tossavainen, Turunen, Kiviniemi, \& Vertio, 2007).

The study described in this article is part of a project called "Promoting the Occupational Well-Being of School Staff-Action Research Project in Finland and Estonia, 2009-2014". This long-term action research project applied a multidisciplinary approach (combined qualitative and quantitative methodology) and the triangulation of data (quantitative initial and final measurement, qualitative interim evaluation on implementation of interventions) The purpose of this study was to test the original OWSS Model from 2005 (Figure 1). This study was based on the following hypothesis: the data collected in Finnish and Estonian schools in 2010 and 2013 corresponds to the original OWSS Model from 2005. The model can be utilized by school staff and administration in school communities, professionals in nursing as well as educators and researchers working in health promotion as several examples.

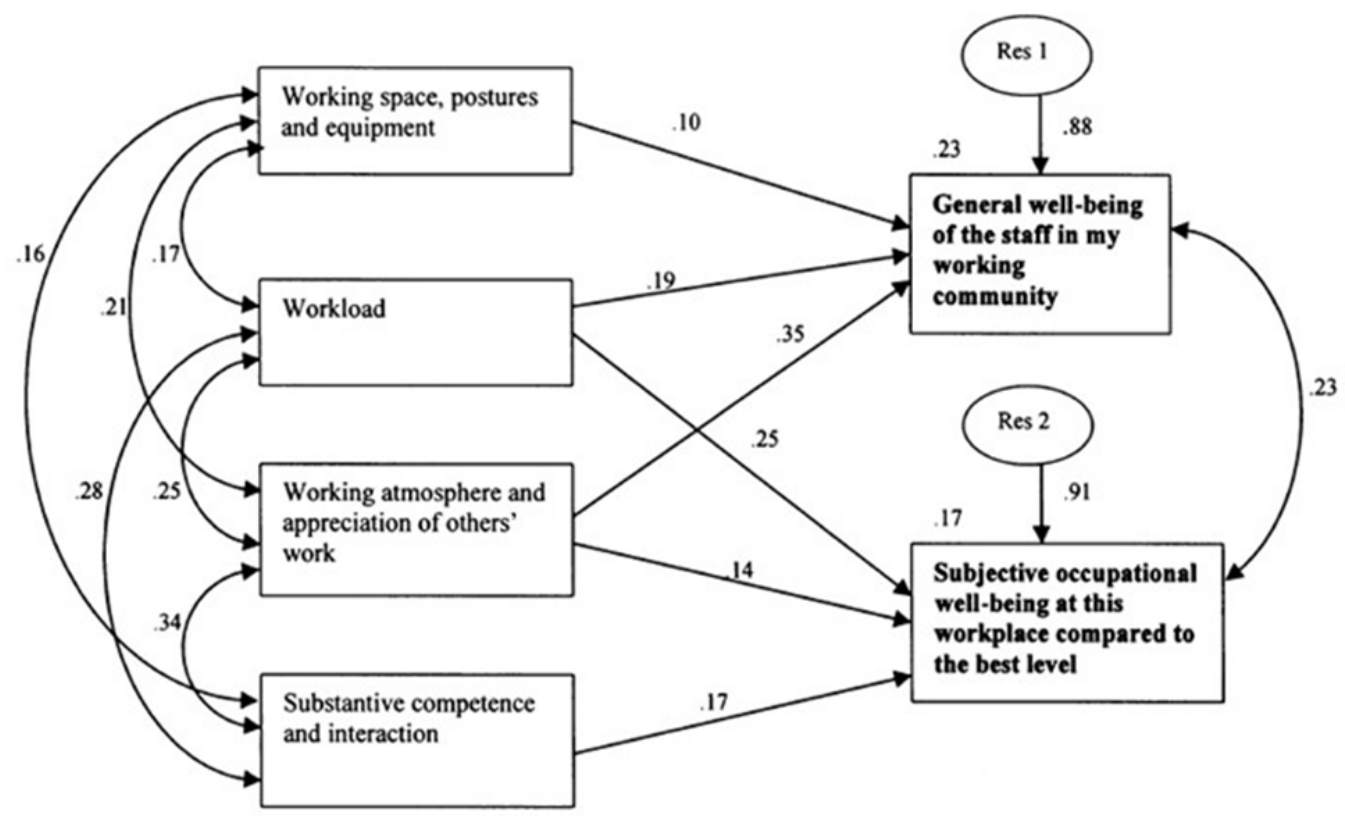

Figure 1. Original Occupational Well-being of School Staff Model (OWSS model), standardized estimates (Saaranen et al., 2007)

\section{Method}

\subsection{Participants and measures}

Schools that were members of the Schools for Health in Europe (SHE) network in Finland and Estonia (Schools for Health in Europe, 2017) were all invited to participate in the action research project. The number of participating schools were 21 in Finland and 40 in Estonia. In 2010, 486 Finnish participants $(N=879)$ responded from 21 public primary and secondary schools, and 1330 Estonian participants $(N=1978)$ responded from 40 
public primary and secondary schools. The response rates were 55\% in Finland and 67\% in Estonia. In 2013, 545 Finnish participants $(N=961)$ responded from 21 schools, and 974 Estonian participants $(N=1871)$ responded from 38 schools. Consequently, response rates were 57\% in Finland and 52\% in Estonia. The schools in Finland and Estonia participated in both the initial and final measurements. Three Finnish schools involved in the initial measurement dropped out due to other obligations and therefore did not participate in the final measurement. Furthermore, three Finnish schools joined the project later, after the initial measurement, and therefore only participated in the final measurement. Background variables and the levels of subjective occupational well-being and the working community's occupational well-being are described in Table 1.

The Well-being at Your Work Index Questionnaire was developed based on literature and has been utilized in previous national and international studies (Saaranen, Tossavainen, Turunen, \& Naumanen, 2006; Saaranen et al., 2012). It includes ten questions relating to background variables, four Likert scale (1-5) questions relating to occupational well-being and actions promoting occupational well-being, and one open question relating to actions that promote occupational well-being. The questionnaire includes individual variables relating to the four aspects of occupational well-being: 1) working conditions, 2) worker and work, 3) working community and 4) professional competence (see Table 2). After each section, the respondent has the chance to answer two open questions and to give additional information pertaining to prior statements or to name other factors affecting occupational well-being.

Table 1. Background variables of school staff members in the years 2010 (study 1) and 2013 (study 2) in Finland (n $=486$ and $\mathrm{n}=545)$ and Estonia $(\mathrm{n}=1330$ and $\mathrm{n}=974)$

\begin{tabular}{|c|c|c|c|c|c|c|c|c|}
\hline \multirow{2}{*}{ Variables } & \multicolumn{2}{|c|}{ Finnish study 1} & \multicolumn{2}{|c|}{ Finnish study 2} & \multicolumn{2}{|c|}{ Estonian study 1} & \multicolumn{2}{|c|}{ Estonian study 2} \\
\hline & $n$ & $\%$ & $n$ & $\%$ & $n$ & $\%$ & $n$ & $\%$ \\
\hline \multicolumn{9}{|l|}{ Background variables } \\
\hline \multicolumn{9}{|l|}{ Sex } \\
\hline Female & 363 & 76 & 402 & 74 & 1135 & 87 & 852 & 88 \\
\hline Male & 114 & 24 & 140 & 26 & 164 & 13 & 116 & 12 \\
\hline Total & 477 & 100 & 542 & 100 & 1299 & 100 & 968 & 100 \\
\hline \multicolumn{9}{|l|}{ Age } \\
\hline$<35$ & 110 & 23 & 110 & 20 & 289 & 22 & 176 & 18 \\
\hline $36-50$ & 227 & 48 & 257 & 48 & 541 & 42 & 400 & 41 \\
\hline$>51$ & 139 & 29 & 173 & 32 & 458 & 36 & 391 & 41 \\
\hline Total & 476 & 100 & 540 & 100 & 1288 & 100 & 967 & 100 \\
\hline \multicolumn{9}{|l|}{ Position } \\
\hline Subject/special teacher & 299 & 63 & 316 & 59 & 572 & 44 & 493 & 52 \\
\hline Primary school teacher & 87 & 18 & 101 & 19 & 282 & 22 & 202 & 21 \\
\hline Principal/school director & 17 & 4 & 23 & 4 & 92 & 7 & 72 & 8 \\
\hline School nurse & 3 & 1 & 8 & 1 & 8 & 1 & 2 & 0 \\
\hline Other support staff & 37 & 8 & 60 & 11 & 116 & 9 & 65 & 7 \\
\hline Other occupational group & 30 & 6 & 30 & 6 & 217 & 17 & 119 & 12 \\
\hline Total & 473 & 100 & 538 & 100 & 1287 & 100 & 953 & 100 \\
\hline \multicolumn{9}{|l|}{ Number of staff in my school } \\
\hline$<20$ & 42 & 9 & 66 & 12 & 72 & 5 & 88 & 9 \\
\hline $21-40$ & 202 & 42 & 180 & 34 & 332 & 26 & 314 & 33 \\
\hline$>41$ & 231 & 49 & 289 & 54 & 886 & 69 & 554 & 58 \\
\hline Total & 475 & 100 & 535 & 100 & 1290 & 100 & 956 & 100 \\
\hline
\end{tabular}




\begin{tabular}{|c|c|c|c|c|c|c|c|c|}
\hline \multicolumn{9}{|c|}{ Total number of years in this position } \\
\hline$<2$ & 39 & 8 & 40 & 8 & 108 & 8 & 88 & 9 \\
\hline $3-10$ & 142 & 30 & 136 & 26 & 436 & 34 & 269 & 28 \\
\hline $11-20$ & 140 & 30 & 187 & 35 & 302 & 23 & 259 & 27 \\
\hline$>21$ & 149 & 32 & 165 & 31 & 446 & 35 & 338 & 36 \\
\hline Total & 470 & 100 & 528 & 100 & 1292 & 100 & 954 & 100 \\
\hline \multicolumn{9}{|c|}{ My contract type } \\
\hline Permanent & 361 & 76 & 437 & 82 & 1155 & 90 & 855 & 89 \\
\hline Temporary & 113 & 24 & 98 & 18 & 133 & 10 & 105 & 11 \\
\hline Total & 474 & 100 & 535 & 100 & 1288 & 100 & 960 & 100 \\
\hline \multicolumn{9}{|c|}{ Level of well-being } \\
\hline \multicolumn{9}{|c|}{$\begin{array}{l}\text { Subjective occupational well-being at } \\
\text { this workplace compared with the best } \\
\text { level }\end{array}$} \\
\hline Very good & 73 & 16 & 100 & 18 & 151 & 12 & 99 & 10 \\
\hline Quite good & 258 & 55 & 285 & 53 & 646 & 51 & 474 & 50 \\
\hline Moderate & 117 & 25 & 113 & 21 & 446 & 35 & 347 & 37 \\
\hline Quite poor & 15 & 3 & 36 & 7 & 32 & 2 & 18 & 2 \\
\hline Very poor & 5 & 1 & 4 & 1 & 3 & 0 & 6 & 1 \\
\hline Total & 468 & 100 & 538 & 100 & 1278 & 100 & 944 & 100 \\
\hline \multicolumn{9}{|c|}{$\begin{array}{l}\text { General well-being of the staff in my } \\
\text { working community }\end{array}$} \\
\hline Very good & 20 & 4 & 34 & 6 & 79 & 6 & 48 & 5 \\
\hline Quite good & 209 & 45 & 255 & 47 & 647 & 51 & 468 & 50 \\
\hline Moderate & 192 & 41 & 175 & 33 & 532 & 42 & 404 & 43 \\
\hline Quite poor & 40 & 9 & 64 & 12 & 17 & 1 & 16 & 2 \\
\hline Very poor & 7 & 1 & 10 & 2 & 3 & 0 & 1 & 0 \\
\hline Total & 468 & 100 & 538 & 100 & 1278 & 100 & 937 & 100 \\
\hline
\end{tabular}

\subsection{Phases of Model Construction and Its Analysis and Further Testing}

The original OWSS Model from 2005 (Saaranen et al., 2007) and the theory (Saaranen, Tossavainen, Sormunen, Laine, \& Turunen, 2015) created based on it were tested and developed with data collected in Finland and Estonia in 2010 and 2013. To test the model, the following endogenous variables based on the original OWSS Model were used: 1) the working community's general staff well-being (GW) and 2) school staff members' subjective occupational well-being at this workplace compared with the best level (SW) (Likert scale 1-5). Both the Finnish and Estonian models had two endogenous variables, which required using a genuine multivariate approach. As exogenous variables, sum variables were used, which were formulated based on the previous OWSS Model and on factoring (Saaranen et al., 2006). As in the original model, the exogenous variables used were: 1) working space, postures and equipment, 2) workload, 3) working atmosphere and appreciation of others' work and 4) substantive competence and interaction. With the Cronbach's alpha coefficient calculated for the factors, the uniformity of a given factor was investigated with the data collected in Finland and Estonia in 2010 and 2013, and with a fluctuation margin of 0.53-0.89 (Table 2). A commonly accepted value falls between $0.60-0.70$ (Hair, Black, Babin, \& Anderson, 2010). The relationship between the endogenous variables and the exogenous variables was unidirectional.

The data from Finland and Estonia collected in 2010 (Finnish study 1 and Estonian study 1) and 2013 (Finnish study 2 and Estonian study 2) were tested using the original OWSS Model. Statistical modelling (parameters estimation) was formulated using the AMOS software, which was also used in the construction of the original 
model. The effects of the standardized estimates of the model were interpreted as follows: the effect is minor if the standardized estimate is $<0.10$, the effect is average if the standardized estimate is around 0.30 , and the effect is significant if the standardized estimate is $>0.50$ (Kline, 1998). The standardized estimates for the models from the Finnish and Estonian studies (2) are presented graphically in Figures 2 and 3.

The Finnish materials were compatible with the original model (Finnish study 1 and 2). While testing the original model with the Estonian materials, it was discovered that its standardized estimates remained minor and that the statistics used for measuring its adequacy and goodness seemed weak. For this reason, the Estonian model was supplemented with one item from the variable working space, postures and equipment to the variable subjective occupational well-being at the workplace compared to the best level. This alteration seemed to improve the Estonian model's suitability (Figure 3).

The suitability and goodness of the structural equation models were evaluated using several criteria (Table 3). A chi-square test was used to measure the model's adequacy in describing the materials; if the p-value of the chi-square test was $>0.05$, the model was deemed acceptable. Other suitability measures used were the Comparative Fit Index CFI ( $>0.95)$, the Normed Fit Index NFI ( $>0.95)$ (Schreiber, Nora, Stage, Barlow, \& King, 2006; Schreiber, 2017) and Root Mean Square Error of Approximation (RMSEA) statistics (the upper limit of acceptable values is 0.06-0.08) (Schreiber et al., 2006).

Table 2. Sum variables of the structural equation model and their alpha coefficient values

\begin{tabular}{|c|c|c|c|c|c|}
\hline $\begin{array}{l}\text { Sum variables of the } \\
\text { aspects of occupational } \\
\text { well-being }\end{array}$ & Individual variables & $\begin{array}{l}\text { Alpha } \\
\text { coefficient } \\
\text { in Finnish } \\
\text { study } 1 \\
(n=486)\end{array}$ & $\begin{array}{l}\text { Alpha } \\
\text { coefficient } \\
\text { in Finnish } \\
\text { study } 2 \\
(n=545)\end{array}$ & $\begin{array}{l}\text { Alpha } \\
\text { coefficient } \\
\text { in Estonian } \\
\text { study1 } \\
(n=1330)\end{array}$ & $\begin{array}{l}\text { Alpha } \\
\text { coefficient } \\
\text { in Estonian } \\
\text { stydy2 } \\
(n=974)\end{array}$ \\
\hline $\begin{array}{l}\text { Working conditions } \\
\text { Working space, postures } \\
\text { and equipment }\end{array}$ & $\begin{array}{l}\text { Uncomfortable working postures have been } \\
\text { considered } \\
\text { Ergonomics when working with a screen are } \\
\text { satisfactory } \\
\text { I have access to my own quiet and } \\
\text { comfortable working space when needed } \\
\text { The equipment and devices needed for my } \\
\text { work are appropriate }\end{array}$ & 0.68 & 0.63 & 0.56 & 0.60 \\
\hline $\begin{array}{l}\text { Worker and work } \\
\text { Workload }\end{array}$ & $\begin{array}{l}\text { The mental workload of my work is suitable } \\
\text { The physical workload of my work is suitable } \\
\text { I am satisfied with my workload } \\
\text { My workload is divided evenly, so that there } \\
\text { is no rush to do work }\end{array}$ & 0.68 & 0.66 & 0.66 & 0.73 \\
\hline $\begin{array}{l}\text { Working community } \\
\text { Working atmosphere and } \\
\text { appreciation of others' } \\
\text { work }\end{array}$ & $\begin{array}{l}\text { In my working community people can openly } \\
\text { discuss things related to work } \\
\text { I get help and support from my colleagues } \\
\text { when needed } \\
\text { I regard my own work in the working } \\
\text { community as important and significant } \\
\text { Personal relationships between workers at my } \\
\text { workplace are fine } \\
\text { There is a spirit of 'fair play' at my } \\
\text { workplace, and there is no harassment of } \\
\text { workers } \\
\text { Superior-subordinate relationships are fine at }\end{array}$ & 0.85 & 0.89 & 0.85 & 0.85 \\
\hline
\end{tabular}


my workplace

There is mutual understanding of colleagues'

work/tasks in my working community

There is trust in others' work input in my

working community

My work is appreciated in my working

community

I have received sufficient education/training

for the tasks I carry out at my work

I have sufficient readiness when acting as a

Professional competence group leader and when the group needs to

Substantive competence communicate

I have sufficient readiness to face special situations (e.g. problematic people/customers)

I have had a possibility to efficiently utilize

my own skills and competence at my work

\section{Results}

\subsection{Finnish Study 1 and 2}

In the Finnish model of 2010 (study 1), working atmosphere and appreciation of others' work explained the working community's occupational well-being, which was also found to have the highest standardized estimate $(0.50)$. Also, working space, postures and equipment were found to have an effect of medium value $(0.13)$, and workload (0.08) had a minor effect on the working community's general occupational well-being. Workload (0.26) and working atmosphere and appreciation of others' work $(0.25)$ were the most significant factors explaining subjective occupational well-being. Additionally, substantive competence and interaction correlated with subjective occupational well-being (0.13).

All sum variables correlated with each other (Table 3 ), and their values were mediate ( $0.33-0.39)$. The exogenous variables explained $35 \%$ of the occupational well-being of the working community and $25 \%$ of the subjective occupational well-being (see squared multiple correlations in Table 3). The equivalent expression of the percentages is the coefficient of determination. The compatibility of material from 2010 with the model was tested, and all compatibility tests ( $\mathrm{x}^{2}, \mathrm{NFI}, \mathrm{CFI}$ and RMSEA) supported its suitability (Table 3 ).

In the Finnish model (study 2; Figure 2), working atmosphere and appreciation of others' work continued to have the most common and significant relationship with the working community's occupational well-being $(0.56)$. It was also found that working space, postures and equipment $(0.10)$ and workload $(0.11)$ were related to the working community's occupational well-being. Working atmosphere and appreciation of others' work were most significantly related to subjective occupational well-being (0.36). Also, workload (0.25) and substantive competence and interaction (0.12) were related to subjective occupational well-being.

The sum variables correlated with each other (Table 3$)$, and the effects between them were of medium value $(0.20$ 0.43 ). Exogenous variables explained $43 \%$ of the working community's occupational well-being and $34 \%$ of subjective occupational well-being. 


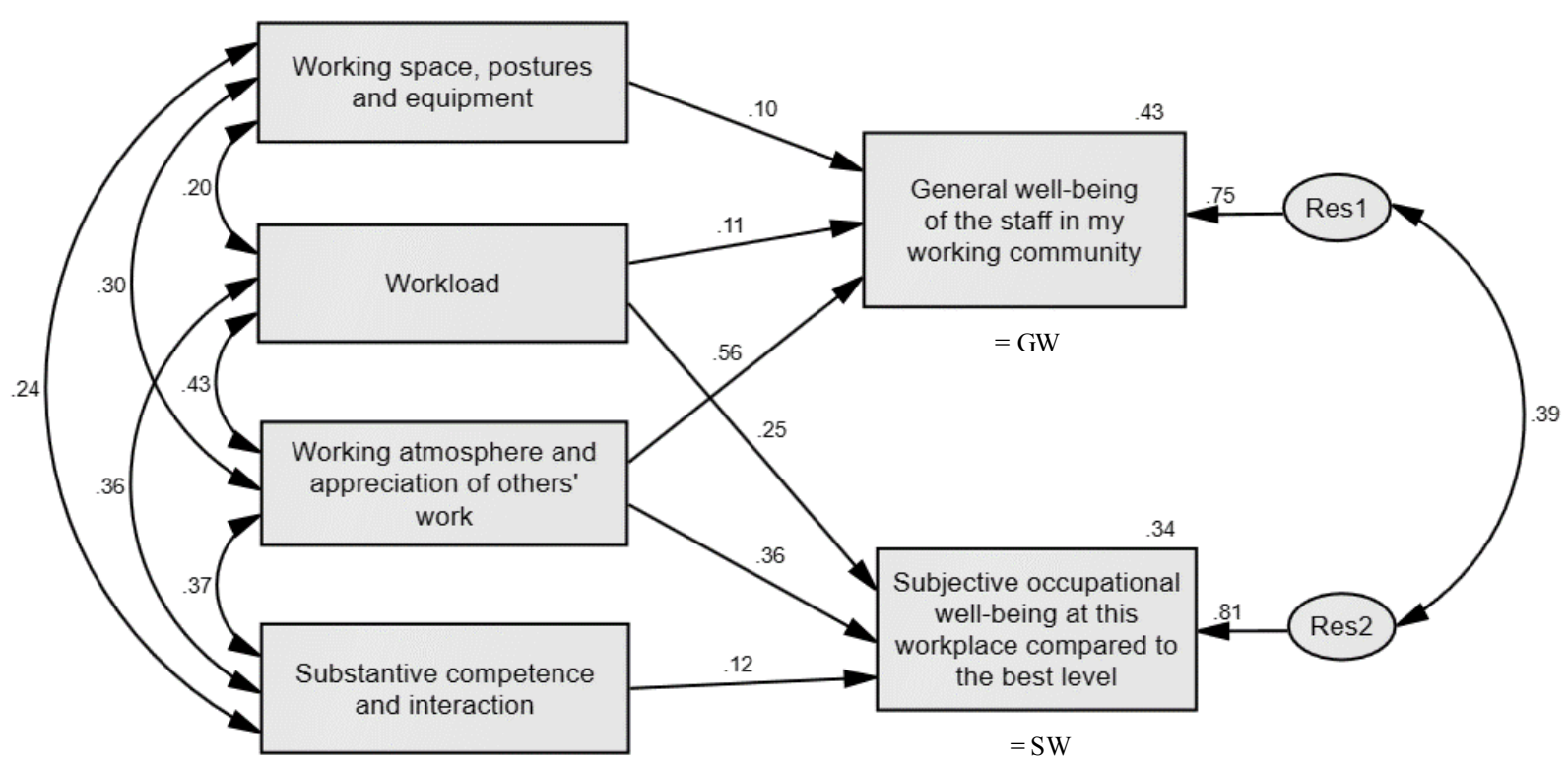

Figure 2. Further tested Occupational Well-being of School Staff Model (Finnish study 2), standardized estimates

\subsection{Estonian Study 1 and 2}

In the Estonian model of 2010 (study 1), working atmosphere and appreciation of others' work (0.27) and working space, postures and equipment $(0.23)$ were the most significant factors explaining the working community's occupational well-being. Moreover, workload had a minor effect on the working community's occupational well-being (0.09). All sum variables explained subjective occupational well-being. Working atmosphere and appreciation of others' work (0.24) and working space, postures and equipment $(0.28)$ had the most significant effect on subjective occupational well-being. Effects of workload $(0.10)$ and substantive competence and interaction (0.04) had medium/minor values in relation to subjective occupational well-being.

Correlations $0.24-0.40$ were found between the sum variables (Table 3). Exogenous variables explained $22 \%$ of the working community's occupational well-being and $25 \%$ of subjective occupational well-being. Tests indicating suitability supported the model's suitability (Table 3 ).

The Estonian model of 2013 (study 2; Figure 3) showed that working space, postures and equipment (0.29) had the strongest correlation with the working community's occupational well-being. Working atmosphere and appreciation of others' work were correlated, with medium values $(0.27)$, whereas the effect of workload $(0.10)$ was medium. All sum variables explained subjective occupational well-being. Working space, postures and equipment (0.33) and working atmosphere and appreciation of others' work (0.23) had the largest effect on subjective occupational well-being. Workload (0.09) and substantive competence and interaction (0.09) had a minor effect on subjective occupational well-being.

Correlations were found between all sum variables, and their values varied between 0.24-0.43. Exogenous variables explained $27 \%$ of the working community's occupational well-being and $30 \%$ of subjective occupational well-being. The model's suitability was tested with different tests, which all supported its suitability (Table 3). 


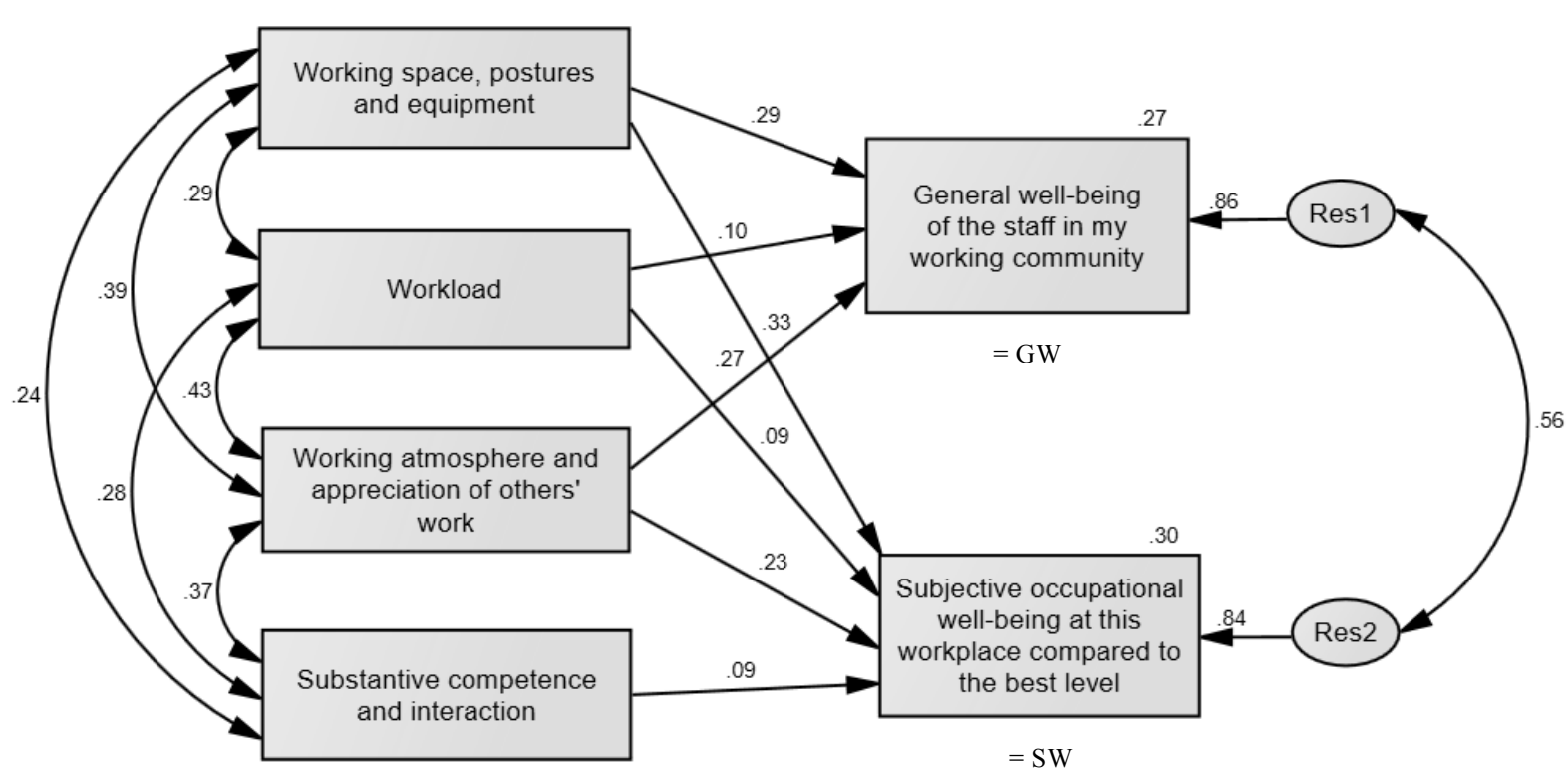

Figure 3. Enhancement Occupational Well-being of School Staff Model (Estonian study 2), standardized estimates

\section{Discussion}

To collect materials for the structural equation models, a previously developed and tested measure was used because its validity and reliability had been found to be good (Saaranen et al., 2007). The amount and content of the study materials are considered appropriate for structural equation models. The volume was larger compared to the materials used for constructing and testing the original OWSS Model. Response rates were reasonably good in both countries. The initial measurement comprised three Finnish schools, which did not participate in the final measurement. Additionally, three Finnish schools participated in the final measurement but not in the initial measurement. These changes were, however, small and had little effect on the whole project. The alpha values of the factors vary between $0.53-0.89$, which provides a reasonable assurance of their functionality. While evaluating the suitability of the Finnish and Estonian models to the materials, acceptable p-values from the chi-square test were produced (except in the 2013 Estonian model). The models' compatibility with the materials was tested using RMSEA, and the results supported the models' suitability. Similar results were obtained from the CFI and NFI compatibility indexes (Table 3). 


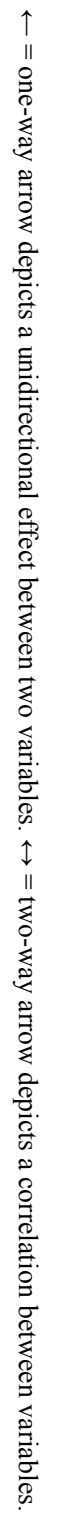
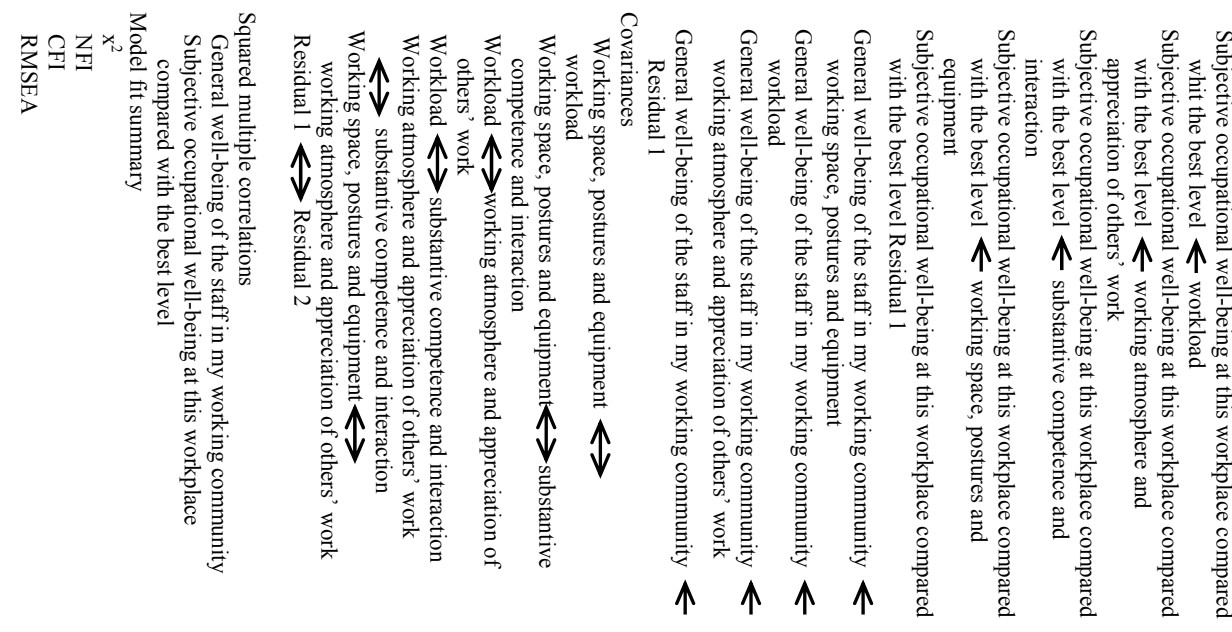

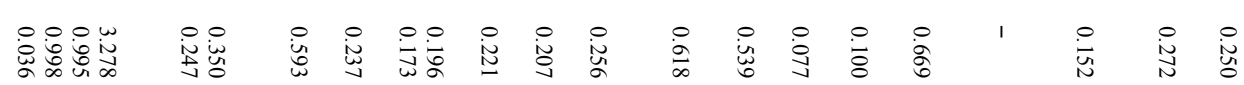

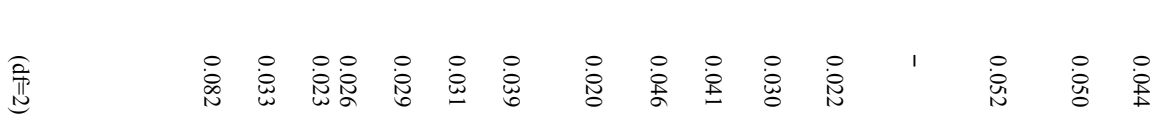

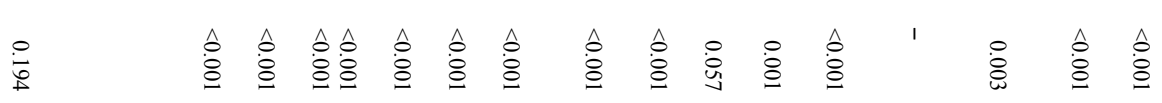

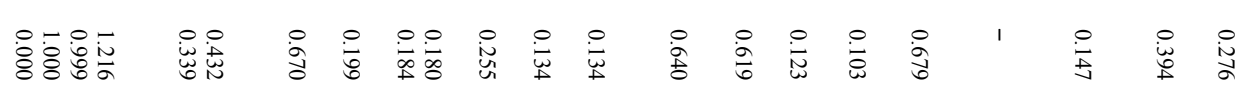

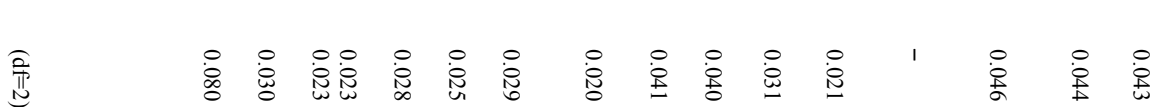

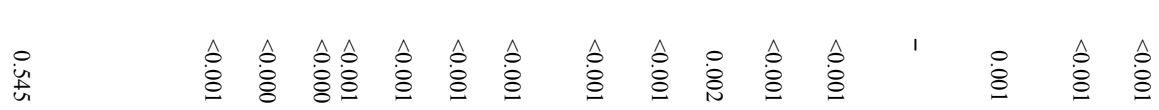

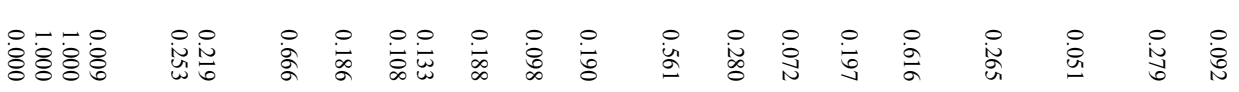

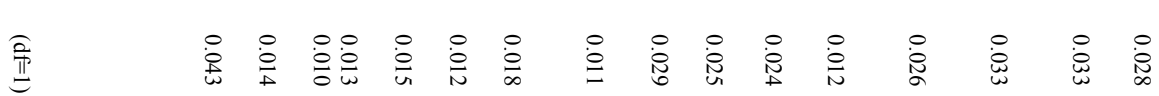

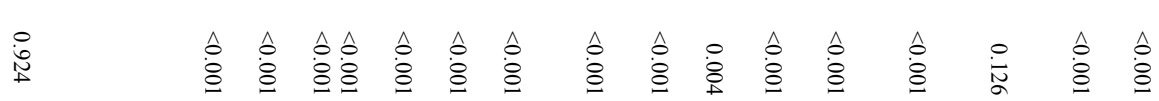

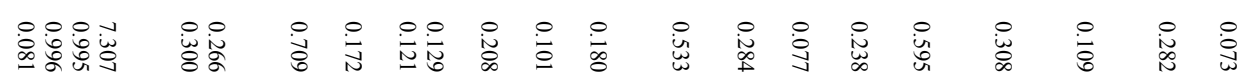

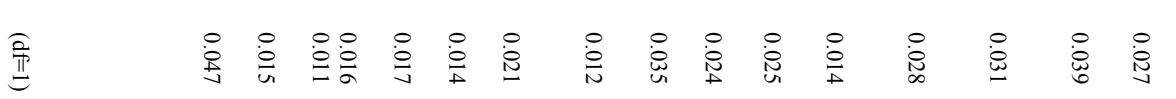

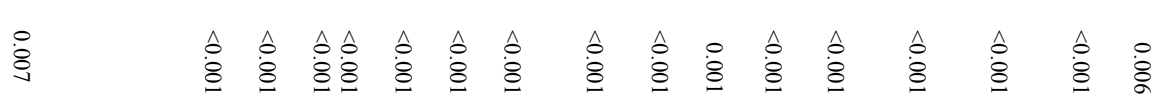

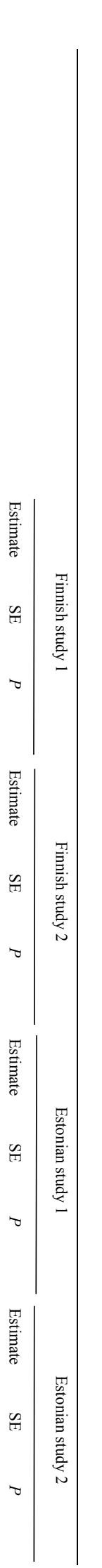

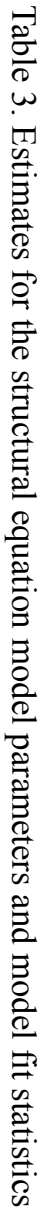


In this article, the original OWSS model from 2005 was further tested and developed with data collected in Finland and Estonia in 2010 and 2013. There are grounds for testing the model because testing and developing a theory is an ongoing process, which already began in 2002. Based on the results, the Finnish materials from 2010 and 2013 are compatible with the OWSS model, which supports the research hypothesis. However, the models did not fit the Estonian materials from 2010 and 2013 without alterations. Therefore, in this respect, the hypothesis was not fully supported by these materials. As a limitation of the study, the intervention may be considered to have a limited impact on the well-being of the school staff. The intervention was based on school-specific development activities, making development activities unique in every school. Occupational well-being is defined in the literature in different ways (Horn et al., 2004; Juniper, 2011), and the self-assessment of occupational well-being can also be understood by people in a subjectively different way.

All sum variables in all models had an effect on occupational well-being, and indirect correlations between $\mathrm{s}$ Num variables were observed. The coefficient of determination in the original model was $23 \%$ for the general well-being of the staff in the working community $(\mathrm{GW})$ and $17 \%$ for subjective well-being at this workplace compared to the best level (SW) (Figure 1). Based on these materials, the corresponding coefficient of determination of the Finnish models was higher (study 1: GW 35\% and SW 25\%; study 2: GW $43 \%$ and SW $34 \%$ ) compared to the original model. Because the Estonian models could not readily be applied to the original OWSS Model, they had to be slightly altered. All in all, the Estonian models exceeded the original model's coefficient of determination, but they fell below the Finnish models' coefficients of determination (study 1: GW $22 \%$ and SW 25\%; and study 2: GW 27\% and SW 30\%). Therefore, the tested Finnish (study 2) OWSS Model is the most applicable of these models (Figure 2).

Testing the original OWSS Model with the new data (2010 and 2013) reasserted the notion that there are four aspects affecting school staff's occupational well-being: working conditions, work and worker, working community and professional competence. This study also reinforced the previous notion that the working community has a powerful impact on occupational well-being, particularly in Finland. The aspect of social support and working community/social support is also underlined in other models, which explain occupational well-being (Saaranen et al., 2007; Bermejo-Toro et al., 2016) It is also noteworthy that despite the enhancements of the Estonian models, the link between the variable of substantive competence and interaction remained insignificant, although this may be partly due to the fact that the questionnaire contained few variables related to this. This poses the future challenge of developing the Well-being at Your Work Index Questionnaire with this aspect in mind.

Workers experience occupational well-being subjectively (Juniper, 2011), which means modelling it can be a challenge. However, this model, which has been developed over a long period of time and has now been subjected to further testing, supports the conceptualization and theorization of occupational well-being. By means of this model, factors pertaining to occupational well-being can be identified, and it serves as a theoretical framework for understanding the phenomenon of occupational well-being. This previously produced model and its applicability have now been tested in two countries. With these justifications, this study further reinforces the previous perception that the structural model of occupational well-being can be used in practice in school contexts to promote occupational well-being. The results also show that the meaning and proportion of the working community in the model has a greater impact than the other sections, which must be taken into account when working to promote occupational well-being.

\section{Conclusions}

This model has been tested and developed in the framework of a long-term action research study. Initially, it was only tested in the Finnish school context, but now it has been tested further and developed in both the Finnish and the international school contexts with four different study materials. The model's further testing has reconfirmed the notion that school staff's subjective occupational well-being and the working community's general occupational well-being should be investigated with broad multi-disciplinary approaches and that they are affected by 1) working conditions (working space, postures and equipment), 2) worker and work (workload), 3 ) working community (working atmosphere and appreciation of others' work) and 4) professional competence (substantive competence and interaction). It seems, however, that working community has a larger effect on occupational well-being than the other aspects. This further testing has proven that the structural equation model continues to be a feasible tool for describing and explaining practice. It has been used and can be used to promote school staff's occupational well-being and to improve public health from the viewpoint of practice, education and theory. The model provides a concrete framework, which enables school staff's active participation in promoting subjective occupational well-being and the entire working community's occupational 
well-being. The occupational well-being index and theory require further future testing and development in varying school contexts (e.g., vocational education and higher education). Moreover, this model can, to some extent, be applied and tested for promoting occupational well-being not only in schools but in other working communities as well.

\section{Acknowledgments}

This work was supported by the Finnish Work Environment Fund, the Finnish Cultural Foundation, the Olvi Foundation, the Finnish Nurses' Education Association and the Academic Federation of Nursing and Health Science Professionals. The authors wish to give special thanks to the Finnish and Estonian school staff and management for their active commitment and participation in this study. In addition, we would like to thank Estonia's National Institute for Health Development and the Department of Nursing Science of the University of Eastern Finland, the support of which has made this research possible.

\section{Competing Interests Statement}

The authors declare that they have no competing or potential conflicts of interest.

\section{References}

Bermejo-Toro, L., Prieto-Ursúa, M., \& Hernández, V. (2016). Towards a model of teacher well-being: Personal and job resources involved in teacher burnout and engagement. Educational Psychology, 36(3), 481-501. https://doi.org/10.1080/01443410.2015.1005006

Demerouti, E., Bakker, A. B., Nachreiner, F., \& Schaufeli, W. B. (2001). The job demands-resources model of burnout. Journal of Applied Psychology, 86(3), 499-512. https://doi.org/10.1037/0021-9010.86.3.499

Hair, J. F., Black, W. C., Babin, B. J., \& Anderson, R. E. (2010). Multivariate data analysis: A global perspective. Upper Saddle River: Pearson.

Hakanen, J. J., Bakker, A. B., \& Schaufeli, W. B. (2006). Burnout and work engagement among teachers. Journal of School Psychology, 43(6), 495-513. https://doi.org/10.1016/j.jsp.2005.11.001

Horn, J. E., Taris, T. W., Schaufeli, W. B., \& Schreurs, P. J. G. (2004). The structure of occupational well - being: A study among Dutch teachers. Journal of Occupational and Organizational Psychology, 77(3), 365-375. https://doi.org/10.1348/0963179041752718

Juniper, B. (2011). Defining employee wellbeing. Occupational Health, 63(10), 25.

Karasek Jr, R. A. (1979). Job demands, job decision latitude, and mental strain: Implications for job redesign. Administrative Science Quarterly, 24(2), 285-308.

Kline R.B. (1998). Principles and practice of structural equation modeling. New York: Guidford Press.

Naidoo, J., \& Wills, J. (2016). Foundations for health promotion. Elsevier.

Saaranen, T., Tossavainen, K., Turunen, H., \& Naumanen, P. (2006). Development of occupational wellbeing in the Fnnish European Network of Health Promoting Schools. Health Education, 106(2), 133-154. https://doi.org/10.1108/09654280610650963

Saaranen, T., Tossavainen, K., Turunen, H., Kiviniemi, V., \& Vertio, H. (2007). Occupational well-being of school staff members: A structural equation model. Health Education Research, 22(2), 248-260. https://doi.org/10.1093/her/cyl073

Saaranen, T., Pertel, T., Kalle, T., Hansen, S., Varava, L., Lepp, K., . . Tossavainen, K. (2012). School staffs' experiences of work and working conditions in Finnish and Estonian schools. Open Public Health Journal, 5 , 55-69.

Saaranen, T., Tossavainen, K., Sormunen, M., Laine, S., \& Turunen, H. (2015). Developing and testing a health promotion Theory-An example of creating a model of school staff's occupational well-being. Schools for health and sustainability. Dodrecht: Springer.

Salmela - Aro, K., \& Upadyaya, K. (2014). School burnout and engagement in the context of Demands-resources Model. British Journal of Educational Psychology, 84(1), 137-151. https://doi.org/10.1111/bjep.12018

Schools for Health in Europe (2017). SHE schools for health in Europe 2017 in focus. Retrieved from: http://www.schools-for-health.eu/uploads/files/SHE_folder_2017(1).pdf

Schreiber, J. B., Nora, A., Stage, F. K., Barlow, E. A., \& King, J. (2006). Reporting structural equation modeling and confirmatory factor analysis results: A review. The Journal of Educational Research, 99(6), 323-337. 
https://doi.org/10.1016/j.sapharm.2016.06.006

Schreiber, J. B. (2017). Update to core reporting practices in structural equation modeling. Research in Social and Administrative Pharmacy, 13(3), 634-643.

Schulte, P., \& Vainio, H. (2010). Well-being at work-overview and perspective. Scandinavian Journal of Work, Environment \& Health, 36(5), 422-429. https://doi.org/10.5271/sjweh.3076

Siegrist, J. (1996). Adverse health effects of high-effort/low-reward conditions. Journal of Occupational Health Psychology, 1(1), 27-41. https://doi.org/10.1037/1076-8998.1.1.27

Vera, M., Salanova, M., \& Lorente, L. (2012). The predicting role of self-efficacyin the Job Demands-resources Model: A longitudinal study. Estudios De Psicología, 33(2), 167-178. https://doi.org/10.1174 /021093912800676439

Warr, P. (1987). Work, unemployment, and mental health. Oxford: Oxford University Press.

Warr, P. (1990). The measurement of well - being and other aspects of mental health. Journal of Occupational Psychology, 63(3), 193-210. https://doi.org/10.1111/j.2044-8325.1990.tb00521.x

\section{Copyrights}

Copyright for this article is retained by the author(s), with first publication rights granted to the journal.

This is an open-access article distributed under the terms and conditions of the Creative Commons Attribution license (http://creativecommons.org/licenses/by/4.0/). 